\title{
Do As We Say, Not As We Do: Teaching Ethics In The Modern College Classroom
}

Thomas T. Amlie, Pennsylvania State University at Harrisburg, USA

\begin{abstract}
In the past decade, there has been an increasing level of distress over the perceived lack of ethics exhibited by members of the accounting profession. This distress has resulted in a call for a greater emphasis on ethics coverage as part of a college-level accounting education. However, one could argue that the various organizations that are leading these calls, and the academic institutions which are charged with implementing this enhanced ethical education, often suffer from ethical failings of their own. The purpose of this paper is to examine the degree to which these organizations "practice what they preach." Recent history is rife with examples of ethical shortcomings on the part of accounting professionals; Enron, Worldcom, and Tyco come to mind as examples which have received extensive media coverage. The resultant public concern over ethics in accounting has led several governmental and professional bodies to mandate or promote codes of ethical conduct. The Congress of the United States, the Securities and Exchange Commission, the American Institute of Certified Public Accountants, and other bodies have all made public pronouncements which explicitly insist upon the importance of ethical behavior. Similarly, many education-related organizations (i.e., universities and accrediting bodies) have taken the position that education in ethics is an essential part of any college-level education. Finally, although the Financial Accounting Standards Board (FASB), which formulates generally accepted accounting practices for commercial firms in the United States, has not made an explicit statement regarding the importance of ethics, the standards which they promulgate are the measure of what is and is not adequate financial disclosure. Since a failure to follow generally accepted accounting principles is usually thought of as misleading and hence, an ethical violation, it could be argued that the FASB is, in fact, charged with "codifying" ethical behavior as far as financial disclosure is concerned. All of the organizations mentioned above can be criticized, to some extent, for ethical failings of their own. Political bodies, such as the Congress and the Securities and Exchange Commission, can often be accused of bowing to special interests and entities which enforce codes of ethics (whether the AICPA in accounting or the American Bar Association in the legal profession or the AMA in the medical profession) are often justly accused of turning a blind eye to all but the most egregious behavior of their members. The FASB, while ostensibly independent, is also subject to pressures in its standard setting process. Finally, the educational establishment has exhibited ethical shortcomings of its own. These problems run from well-publicized institution-wide problems in discrimination and college athletics down to the individual class and faculty member who engages in less-thanethical behaviors. The paper will examine the recent ethical failings in business and the resultant calls for greater ethical behavior on the part of the accounting profession. A brief summary of some of the literature related to ethical education and development will then be presented. After this, the behaviors of the various regulatory, standard setting and educational institutions will be examined to determine the extent to which their individual behaviors coincide with their stated positions on ethical behavior and the degree to which these behaviors match the standards that we are encouraged to teach to our students.
\end{abstract}

Keywords: Ethics; Education; Professionalism

I shall the effect of this good lesson keep, As watchman to my heart. But, good my brother, Do not, as some ungracious pastors do, Show me the steep and thorny way to heaven; Whiles, like a puff'd and reckless libertine, Himself the primrose path of dalliance treads, And recks not his own rede. (Hamlet, Act 1, Scene 3, 50-56)

\section{INTRODUCTION}

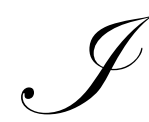

$\mathrm{n}$ the recent past, there have been several well-publicized instances in which firms have engaged in lessthan-adequate financial reporting (Enron, WorldCom, Xerox, etc.). In some instances these failings have led, at least in part, to the collapse of the companies involved. In other instances, firms have had to 
restate their reported earnings. In all cases, though, these situations have been held up as examples of unethical practice by those in the accounting profession. These ethical lapses by accountants have led to increased calls for improvement in the area of ethics instruction in business schools. The question to be addressed in this paper is whether ethical instruction, when provided by individuals and organizations with their own ethical shortcomings, can hope to systematically improve the ethical sensitivity of business school students, in general, and accounting students, in particular.

Although few will doubt that professional and educational institutions suffer from ethical failings, disagreements could arise as to the importance of these shortcomings. It could be argued that since the specific ethical or professional norms that have been violated by accountants are narrow in scope, evaluations of the broader general ethical behavior of the educational, political, and professional institutions which create accountants is not relevant. That is, some may claim that it is possible that budding accountants can be taught adherence to a professional code of ethics within a system and a culture, which itself violates ethical norms related to other aspects of behavior, and that the ethical and moral behaviors exhibited in the environment, within which accountants are trained are therefore irrelevant. Others, however, could argue that an essential component of any effective ethics instruction is the moral example set by the teacher and the academic organization within which the students learn.

The two questions that need to be addressed in this paper are: 1) can we expect ethical behavior on one dimension (i.e., the professional duties of the accountant) from one whose overall ethical orientation is suspect and 2 ) is it possible to develop the ethical sensibilities of students when the system within which they learn, and will ultimately work, is ethically impaired?

The remainder of this paper is organized as follows. The next (second) section provides a discussion of the increased calls for ethical behavior, sensitivity, and education and the quarters from which these calls have been made. The third section includes a brief review of some of the literature involving ethical or moral development and the "teaching of ethics," as well as literature which may shed light on the question of whether it is reasonable to expect ethical behavior along one dimension of behavior whilst acknowledging unethical behavior along other dimensions. The fourth section provides a brief review of some of the behavioral and ethical shortcomings of the various groups and institutions which are a party to this debate. Finally, the fifth section provides some concluding thoughts, as well as some suggestions for future research in this area.

\section{INCREASED CALLS FOR ETHICS AND ETHICAL INSTRUCTION}

Calls for improved ethics instruction have come from several different quarters. The American Association of Collegiate Schools of Business (AACSB) requires, as a condition for accreditation, that ethics instruction be included in any program of study in business. The American Institute of Certified Public Accountants (AICPA) has long had a code of professional ethics, breaches of which may make the offender subject to disciplinary action. Similarly, state regulatory and licensing agencies and the Securities and Exchange Commission have the power to impose sanctions on those accountants who fail to adhere to codes of professional conduct. The Financial Accounting Standards Board (FASB), while not explicitly promulgating a code of ethics, has established a conceptual framework which includes requirements that accounting information be "neutral" and "free from bias". Furthermore, since FASB pronouncements are held to be Generally Accepted Accounting Principles ("the rules" of financial reporting), violations of FASB pronouncements could be viewed as prima facia evidence of improper and unethical behavior.

In addition to these private sector entities, governmental agencies and commissions have also been trying to improve the ethical behavior of accountants. Calls for improved ethics among accountants have come from the President, members of Congress, and successive heads of the Securities and Exchange Commission.

Congress, through the passage of the Sarbanes-Oxley act, has attempted to prohibit those behaviors or relationships which many believe lead to ethical conflicts and lapses. Accounting firms which provide audit services are no longer allowed to provide the more-lucrative consulting services to their audit clients, under the assumption that the auditor may overlook accounting irregularities in order to not jeopardize the consulting relationship. Similarly, "auditor rotation" has been mandated so that relationships between auditor and client do not become too "cozy." 


\section{CAN ETHICAL BEHAVIOR BE TAUGHT?}

Myriad studies have been conducted over the past several decades in an attempt to determine the effectiveness of ethics instruction in increasing the ethical sensitivity or behavior of students (Davis and Welton, 1991; Duizend and McCann, 1998; Wynd and Mager, 1989). The results of this research have been largely mixed, with some researchers finding that "interventions" (i.e., ethics education) increase some aspects of students' ethical sensitivity, while other researchers find no apparent effect. Arlow and Ulrich (1985, cited in Weber, 1990) found that after a period of four years the apparent improvement in students' ethical behavior had faded away.

Some studies (Davis and Welton, 1991; Stevens, et al. 1993) document an increase in ethical sensitivity as undergraduate students progress through their programs of study, irrespective of the presence of a dedicated ethics course. The cause of this finding is still subject to debate: it could be ascribed either to the moral maturation of students or to (hopefully) pervasive ethics coverage in many of their functional-area courses.

It has been argued that the placement or sequencing of a business ethics course within a curriculum will impact the efficacy of that course. Ethics courses are often offered as freshman or sophomore level courses, and often rely upon case studies (Pamental, 1989). It has been argued (Pamental, 1989) that since students at this stage are not yet well versed in the intricacies of the functional areas of business, these case-study-based ethics courses will be of minimal effectiveness.

\section{ETHICAL DEVELOPMENT OF STUDENTS}

One framework within which "moral growth" has been explained was provided by Lawrence Kohlberg. Kohlberg's framework includes, at the lowest level, adhering to stated rules in order to avoid punishment or in order to advance one's interests. Many well-publicized ethics instruction vehicles appeal to this level of development. Students are taken to prisons to see the penalties for violating the law, and ex-convicts are brought in as speakers in an attempt to get the students "scared straight".

For those who operate at this lowest level, it would seem reasonable to assume that once the threat of punishment is withdrawn, the ethical behavior will be withdrawn as well (unless it continues to advance the individual's self-interest). If we believe that this "rule-following" behavior is an acceptable outcome of ethics instruction, then it may be inferred that the ethical climate within which students are educated is not as important. We would essentially be assuming that it is reasonable to expect ethical behavior along one dimension (i.e., the professional responsibilities of accountants) while allowing for unethical behavior along other dimensions of behavior. One could argue that attempting to teach ethics without concern for the ethical environment in which this teaching is taking place is essentially appealing to the lowest stages of moral development. Although it may be possible to foster within students obedience to rules and regulations, this obedience will not be due to an increased moral development.

At the other extreme of Kohlberg's framework - at the highest or "post-conventional" level - would be concern with a "social contract" ("level 5") and universal and consistent ethical principles ("level 6"). At these levels, the actor is not concerned with the punishment or extrinsic reward associated with good or bad behavior. Rather, adherence to a code of ethical behavior is viewed as good in and of itself. If students do not have a role model to emulate - i.e., one who adheres to a consistent code of ethics (or mode of behavior) because it is good in and of itself - they may not be guided to that higher level of moral development. If students fail to mature morally (attain higher levels of moral development), then there may be no intrinsic or psychic desire on their part to act ethically.

Clearly, one problem with "level 6" moral development is that the actor is no longer concerned with external validation of his actions; instead, he is concerned with adhering to his consistent internal code. This, or course, begs the question of where the actor's moral code came from. If it is affected by the example set by the faculty members and professional organizations to which the actor is exposed, then the ethical behavior of these influences is of paramount importance. 
Some studies of ethical development among students indicate that any increases in ethical behavior are transient, persisting only for a short period of time (Arlow and Ulrich, 1985, cited in Weber, 1990). The short-lived effects of ethical instruction may be due in part to this lack of higher-order moral development. As time progresses, and students see unethical behavior go unpunished, the perceived threat of punishment recedes, and the student is left with no compelling reason to act ethically.

\section{THE IMPORTANCE OF ENVIRONMENT AND ROLE MODELS}

Several authors have noted that the environment or organization within which one operates and the perceived ethics of others can have a profound impact on the ethical behavior of organization members (Tyson, 1990; Sims and Brinkmann, 2003). Alternatively, Tyson (1992) interpreted the results of a study as indicating that the perceived honesty of others has little impact on behavior; however, his results (as presented), are open to alternative interpretations. There is substantial anecdotal evidence and speculation that the "organizational culture" has a substantial impact on the ethics of members of an organization.

Beyond the organizational culture in general, the ethical tone set by top management has been posited to have a strong influence on the corporate culture as well as the ethical behavior of persons within the organization (see Sims and Brinkman, 2002, for a good discussion of the effect of the behavior of firm leadership). It does not seem unreasonable to view the role of faculty members in the same light that we view the role of corporate management. The behavior and deportment of those who might be seen as "role models" has long been acknowledged to affect moral decision making. In 1808, Thomas Jefferson, in a letter of advice to young Thomas Jefferson Randolph, recalled that:

I had the good fortune to become acquainted very early with some characters of very high standing, and to feel the incessant wish that I could ever become what they were. Under temptations and difficulties, I would ask myself what would Dr. Small, Mr. Wythe, Peyton Randolph do in this situation? What course in it will insure me their approbation?

In a similar spirit, Brackner (1992) noted that at one time,

Universities considered the moral development of their students to be an integral part of their mission and devoted great efforts to this end.....In addition, efforts were made to surround students with living examples of rectitude and principled behavior. University presidents placed great emphasis on the character of candidates in appointing professors to their faculties. In his inaugural address as the president of Yale University in 1871, Noah Porter declared: 'The most efficient of all moral influences in a college are those which proceed from the personal characters of the instructors... a noble character becomes light and inspiration, when dignified by intellectual power and attainments.'

David Callahan, Director of the Hastings Center, noted in a Wall Street Journal editorial, “...it is the task of those who teach ethics.....to try to instill good moral habits, to help students to arrive at correct moral judgments, to lead them by precept, and by example, and by exhortation" (Callahan, 1987). In almost all fields of endeavor, exhortations to teach ethical behavior "by example" can be found.

In addition to the rhetorical calls for faculty to set a better ethical example, there is empirical data to support the assertion that the behavior of faculty is important to the ethical development of students, and that faculty do serve as role models whether for good or ill. David, Anderson, and Lawrimore (1990) published the results of a survey which indicated that $92 \%$ of respondents (business school graduates) indicated that the personal actions of faculty members were important in the development of the students ethical values, and that $94 \%$ of respondents indicated that faculty behavior was important in imparting ethical values to students. Surprisingly, however, only $15 \%$ of the respondents indicated that their ethical values were influenced by their business professors. One possible explanation for this seemingly incongruous result is that many faculty members may not take any clear ethical positions in the classroom. More than $90 \%$ of students indicate that they could be affected by the faculty member's moral posture, and yet apparently the opportunity is not being seized. 


\section{THE ETHICAL BEHAVIOR OF THE VARIOUS CONSTITUENCIES}

As was noted in the introduction, the institutions leading the calls for ethical instruction, and the academic community charged with this instruction, often seem to suffer ethical lapses of their own. First and foremost, the colleges and universities which are supposed to be inculcating ethical values in students exhibit shortcomings along a number of dimensions, from well-publicized failings at the institution-wide level down to the performance of the individual faculty members in the classroom.

\section{The University: Institution-wide}

At the institution-wide level, there seems to be a never-ending stream of reports of aberrant behavior. Students see high-level administrators (e.g., presidents) publicly charged with fabrications on their resumes, plagiarism, and mis-use of institutional resources. Additionally, these same administrators tolerate (if not aid and abet) illegal and/or unethical behavior in major sports programs. University presidents may actively engage in aberrant behavior (e.g., the recruitment of suspect transfer students to benefit the athletic program), or may make decisions without regard to the ethical implications of those decisions. The most blatant example of such behavior is the recruitment of Athletic Department personnel (i.e., coaches) based on their win/loss records, irrespective of the well-documented histories of illegal and/or unethical behaviors.

\section{The University: School of Business}

At the School (or College or Department) of Business level there are often examples of ethically suspect behavior which students may or may not see. At many schools the publication record of faculty is the prime criteria in promotion and tenure ( $\mathrm{P} \& \mathrm{~T}$ ) decisions, (almost) irrespective of the faculty member's performance in the classroom. As the Dean of the College of Business at Ball State University noted, "Administrators continue to evaluate a faculty member's annual performance by teaching, research, and service, but what this REALLY means is "how many articles did you publish in refereed journals last year?" (Richardson, 2003). In addition, the evaluation of faculty publications is often made simply on a "number count" (i.e., so many publications in peerreviewed journals) irrespective of the quality (or lack thereof) of those publications. At the other extreme, some institutions do not count publications in peer-reviewed pedagogical or practitioner journals regardless of the contribution those publications may make to the field.

There are other aspects of promotion and tenure decisions within departments which also raise ethical questions. Papers by Norgaard (1989) and Rama, et al. (1997) provide weak evidence that gender-based discrimination may exist in P\&T decisions. Additionally, in those instances where classroom performance is considered in the P\&T decision, this performance is usually measured by what many view as a suspect student evaluation process (Martin, 1998). Although education is coming to be considered a "business" with students as the "customers" (Van Valey, 2001), having students (who possess one set of motivations and desires) evaluate faculty (with a different set of motivations and desires) can lead to students evaluating faculty not on the quality of the instruction which they provide but rather on whether the faculty member satisfies the immediate desires of the students.

Another item of note in the area of departmental behavior is the treatment or respect given to the area of ethics. Hosmer (1999) found, via a survey of individual subscribers to Business Ethics Quarterly, that those who teach business ethics often perceive themselves and their courses as being marginalized within Schools of Business. Publications in ethics-related journals are given less credence, student evaluation in ethics courses are discounted (since they are "soft" courses), and there is a perception that rewards (i.e., salaries) for those who teach ethics are less than those in other functional areas. A small minority of schools require a separate course in ethics, with most schools opting for an "integrated instruction" approach where ethics coverage is provided throughout the curriculum (Solberg, et al., 1995). Although theoretically such an approach would be an effective means of constantly reinforcing the value of ethics in business, many schools give complete discretion to faculty members in how ethics is integrated into their courses. Solberg, et al. (1995) noted that only $30 \%$ of schools responding to their survey actually required faculty to integrate ethics into their courses, and of those $91 \%$ gave faculty members complete "discretion in determining the type, amount, and scope of ethics coverage." Given that many faculty members may 
feel uncomfortable covering ethics or may question the value of such coverage, such complete discretion opens the door to minimal or non-existent coverage of ethics topics.

As a final note, a cursory examination of the literature regarding ethics programs in Schools of Business will reveal that many papers are prefaced by statements that ethics coverage is being implemented in response to AACSB accreditation requirements, with a cursory acknowledgement that "there have been ethical lapses." Although the authors are not aware of any data to support this contention, it could be argued that many schools are implementing these programs not out of an innate desire to increase the ethical sensibilities of their students but rather simply as a means of satisfying accreditation requirements.

\section{The University: Individual Faculty}

The ethical behavior of individual faculty members is the most readily apparent to students. If we accept that the efficacy of ethics instruction will be impacted by student perception of the perceived ethical orientation of faculty members, then any apparent ethical shortcomings of faculty members deserve close scrutiny. In many instances faculty members cite "academic freedom" as a defense when questions are raised as to their professional behavior in administering their classes.

Several empirical studies have examined the ethical orientation or standards of faculty in accounting (Engle and Smith, 1990), economics (Laband and Piette, 2000), and information systems (Shenas and Derakshan, 1994). These papers generally provided faculty members with behaviors which are generally viewed as unethical (e.g., canceling office hours excessively, using institution resources for personal gain, exchanging better grades for consideration of various forms, etc.) and asked faculty to rank them on a scale from "completely ethical" to "completely unethical." Although faculty members on average rated these aberrant behaviors as "unethical" to some degree, a disturbing number of respondents rated clearly unethical behaviors (e.g., exchanging sex for grades) as only "somewhat unethical."

Beyond these empirical studies of educators' stated views of certain behaviors, there are many day-to-day behaviors which faculty may exhibit which may cast doubts upon their probity and integrity. Favoritism in grading, excessive cancellation of or tardiness for classes, arbitrary exercise of authority, or poor preparation for classes are among many types of poor behaviors which students can readily perceive. Even a practice as seemingly benign as "grading on a curve" may signal to students that, although there are stated standards of performance, these standards are discounted in the interests of attaining a given grade distribution. At the extreme, the well-documented existence of rampant "grade inflation" (Sonner, 2000 and Nagle, 1998) signals to students that there is not necessarily a strong relationship between merit and reward.

In discussing "ethics in the classroom" with students, one area of concern which is often raised by students is that of academic dishonesty. The majority of students seem to have strong views on this topic; they occasionally see peers and colleagues engaging in academic dishonesty, often without any apparent penalty. Students have cited examples where they have observed others "cheating" on examinations in full view of the faculty member, again without any apparent penalty. These students often come to the very reasonable conclusion that, for that faculty member at least, "ethics" or "honesty" is irrelevant.

How faculty respond to ethical violations by students also have an impact on student ethical growth. For example, one could argue that the lack of punishment for unethical actions encourages students to revert to stage 1 moral development; or alternatively, if we assume that the stages of moral development are cumulative, then the absence of punishment inhibits "stage 1" moral reasoning, making any subsequent growth difficult.

How faculty members deal with academic dishonesty in the classroom is one way in which a very clear and unequivocal message can be conveyed to students regarding "right and wrong". In discussion with fellow faculty members, however, it is apparent that no such clear and unequivocal message exists. Some faculty members maintain that they never have instances of academic dishonesty in their courses; such a claim invites speculation that the faculty member is simply oblivious or is unconcerned with the issue. Among those who do acknowledge the existence of academic dishonesty, the sanctions imposed on students range from "none" to "require the student to 
repeat the assignment" to "give the student as "F" on the assignment" to "give the student an "F" for the course" to "proceed with formal charges through appropriate channels". The failure to exact a meaningful penalty for academic dishonesty signals to students that, although we have expectations and rules regarding ethical behavior in the classroom, we are not that serious about enforcing them. Furthermore, the wide range of possible outcomes for these students suggests to them that inappropriate behavior is acceptable as long as either (a) you are not caught, or (b) you are caught by a faculty member who is unconcerned with the issue.

\section{Accounting Standard Setters}

The Financial Accounting Standards Board (FASB) is charged with promulgating "Generally Accepted Accounting Principles" (GAAP). Although the FASB has not formally proposed a code of ethics or standards of ethical conduct for accountants, their pronouncements are essentially "the rules" for financial reporting in the United States, and failure to follow these pronouncements could be considered prima facia evidence of unethical behavior.

According to Statement of Financial Accounting Concepts No. 2 (promulgated by the FASB), accounting information should be prepared with an eye towards "neutrality;" that is, accounting information should fairly and accurately represent economics events and conditions, without regard for the positive or negative impact upon the parties involved. Unfortunately, one could question whether the FASB adheres to this notion of "neutrality" in its formulation of generally accepted accounting principles. The most well-known example of such questionable practices involves the events leading up to the publication of Statement of Financial Accounting Standard No. 123, which dealt with accounting for stock options. The academic and investing community, by and large, believed that the fair value of stock options granted to management and executives should be treated as an expense on the firm's income statement. Although there are and were valid concerns regarding the appropriate measure of fair value for these instruments, the general consensus was (and is) that some measure of fair value should be recorded as an expense. Companies which rely heavily on stock option grants to their executives and officers would suffer reduced earnings as a result of such a ruling, and therefore lobbied their elected representatives in an attempt to derail the project. After several members of Congress threatened to strip the FASB of its standard setting authority, the final pronouncement by the FASB left firms with the option of either recording these options at their fair value, or continuing to treat them as a "costless" form of compensation.

Essentially, one could view the FASB's actions as abrogating their duty to establish fair and relevant accounting standards in order to avoid unpleasant consequences, even while practicing accountants are encouraged to maintain their objectivity and independence in the face of threats to their livelihood. At a recent academic conference (2003 Southeast American Accounting Association conference) a member of the FASB stated that the FASB's actions were not due to a "lack of calcium" (i.e., a lack of "backbone"), but rather as a measured action necessary to maintain the FASB's viability as an "independent" standard setting body. As one observer noted, the stated position could be summarized as "he who fights and runs away, lives to fight another day."

Similar conflicts have emerged in a number of other technical accounting areas; the treatment of goodwill, the procedures for accounting for acquired companies, and the disclosure of off-balance-sheet financing arrangements are all areas where the FASB has been subject to intense political pressures from lawmakers whose constituents have a vested interest in the resolution of these topics.

\section{Professional and Regulatory Groups}

The American Institute of Certified Public Accountants (AICPA) is the nation-wide professional organization for Certified Public Accountants (CPAs). Many in the accounting profession would have the AICPA viewed in the same manner as the American Bar Association or the American Medical Association are viewed. The AICPA has a code of ethics (or "code of professional conduct"), violations of which leave the offending member open to sanction by the AICPA.

There has been intermittent research into how vigorous the AICPA is in prosecuting actions against members who have had ethical failings. From 1990 through 2000, the Securities and Exchange Commission sanctioned about 280 accountants; the AICPA imposed additional actions in less than one-fifth of these cases 
(Hilzenrath, 2001). Although this appears to be an egregious lack of ethics enforcement, it should be noted that approximately one-third of the accountants sanctioned by the SEC were not AICPA members and were therefore beyond the reach of AICPA sanctions. Measurement of the aggressiveness with which the AICPA investigates ethical lapses is impeded both by the nature of the reporting system which leads to AICPA investigations, as well as by the nature of the AICPA investigatory process. Non-CPAs may not be in a position to know that an ethical lapse has occurred, and CPAs may be hesitant to bring an action against another member of the profession (Graber, 1979). Additionally, if the investigation reveals no wrongdoing on the part of the CPA, information related to the complaint is not publicly disseminated, so it becomes difficult to assess the standard of proof the AICPA requires.

One indicator of the esteem which the AICPA enjoys as a professional organization is that it is now often referred to as a "trade group" rather than a "professional organization". To many it seems that the actions of the AICPA are motivated more by a desire to protect their memberships economic interests and their own position in society, rather than a desire to increase the professionalism of the accounting profession.

\section{SUMMARY \& CONCLUSIONS}

There can be little doubt that the educational and professional environments within which accountants (and accounting students) operate are rife with ethical shortcomings. The importance of these shortcomings in light of the increased emphasis on "teaching ethics" is hard to overemphasize. Just as the business press is full of exhortations for corporate leadership to lead by ethical example, countless commentators have argued that an essential component of any attempt to "teach ethics" is the firm moral example set by the teacher. If the behavior of professional and educational institutions is inconsistent with the values that we are trying to instill in our students, then the lessons we are trying to impart may be viewed as insubstantial preaching.

If we believe that long-term improvements in ethical behavior are dependent upon the moral growth of the individual, and if we believe that this moral growth is dependent upon students being exposed to consistent and universal ethical values, then substantial changes are needed within academia in order to foster this moral growth. Loeb (1990) and Sauser (1990) acknowledge this interdependency in their suggestions for a code of ethics for academic accountants (Loeb, 1990) and business professors (Sauser, 1990).

An important area of future research would examine the degree to which the assumptions made in this paper are borne out by empirical evidence. A key assumption made by the authors is that the moral and ethical behaviors, which students are exposed to, influence their moral development. If this assumption were proven, it would have serious implications for the way in which academic institutions and their agents operate. Although one extant empirical study supports this assertion (David, et al., 1990), this is clearly a question which deserves to be revisited.

\section{AUTHOR INFORMATION}

Thomas T. Amlie is an Assistant Professor of Accounting at Penn State University in Harrisburg. His research interests are in the areas of financial disclosure and professional ethics.

\section{REFERENCES}

1. Brackner, James W.: 1992, "History of Moral and Ethical Education”, Management Accounting, July 1992, p. 22.

2. Callahan, David: 1987, "Teaching Ethics, Morally", Letters to the Editor, The Wall Street Journal, October 1, 1987, p 1.

3. David, Fred R., L. McTier Anderson, and K. W. Lawrimore: 1990, "Perspectives on Business Ethics in Management Education”, S.A.M. Advanced Management Journal, v55, n4, p26 - 32.

4. Davis, James R. and Ralph E. Welton: 1991, "Professional Ethics: Business Students Perceptions”, Journal of Business Ethics v10, n6, p. 451 - 463.

5. Duizend, Johnny, and Greg K. McCann: 1998, "Do Collegiate Business Students Show a Propensity to Engage in Illegal Business Practices?", Journal of Business Ethics v17, n2, p 229 - 238. 
6. Engle, Terry J. and Jack L. Smith, "The Ethical Standards of Accounting Academics", Issues in Accounting Education, Spring, 1990, v5, n1, p. 7.

7. Graber, Dean E.: 1979, “Ethics Enforcement: How Effective?”, The CPA Journal, (September), v 49, n9, p $11-17$.

8. Hilzenrath, David S.: 2001, “Auditors Face Scant Discipline; Review Process Lacks Resources, Coordination, Will”, The Washington Post, December 6, 2001, p A-1.

9. Hosmer, LaRue Tone, “Somebody out there doesn't like us: A study of the position and respect of business ethics at schools of business administration", Journal of Business Ethics, Nov 1999, v22, n2, p 91 - 106.

10. Laband, David N. and Michael J. Piette, "Perceived Conduct and Professional Ethics among College Economics Faculty", American Economist, Spring 2000, v44, n1, p24.

11. Loeb, Stephen E.: 1990, “A Code of Ethics for Academic Accountants?", Issues in Accounting Education, v5, n1, p 123.

12. Martin, James R., "Evaluating faculty based on student opinions: Problems, implications, and recommendations form Deming's theory of management perspective", Issues in Accounting Education, 1998, v13, n4, p1079.

13. Nagle, Brian, “A proposal for dealing with grade inflation: The relative Performance index", Journal of Education for Business, Sept 1998, v74, n1, p 40.

14. Pamental, George L. 1989: “The Course in Business Ethics: Can it Work?”, Journal of Business Ethics 8, p. $547-551$.

15. Rama, Dasaratha V., K. Raghunandan, Lawrence B. Logan, and Beryl V. Barkman: 1997, “Gender Differences in Publications by Promoted Faculty”, Issues in Accounting Education, v12, n2, p353.

16. Richardson, Lynne: 2003, "A Challenge to Business Education”, Mid-American Journal of Business, Spring, 2003, 18/1, p. 5.

17. Sauser, William I., Jr.: 1990, "The Ethics of Teaching Business: Towards a Code for Business Professors, SAM Advanced Management Journal, Autumn 1990, v55, n4, p. 33

18. Shenas, Delavar and Sepehr Derakshan, "The Ethics of Business Information System Academics", International Journal of Management, v11, n2, June 1994, p. 690.

19. Sims, Ronald R. and Johannes Brinkmann: 2003, "Enron Ethics (or: Culture matters more than codes)", Journal of Business Ethics, v45, n3, p 243 - 256.

20. Sims, Ronald R. and Johannes Brinkmann: 2002, "Leaders as Moral Role Models: The Case of John Gutfreund at Salomon Brothers", Journal of Business Ethics, v35, n4, p. 327 - 339.

21. Solberg, Joseph, Kelly C. Strong, and Charles McGuire Jr.: 1995, "Living (Not Learning) Ethics”, Journal of Business Ethics, v14, n1, p71 - 81 .

22. Sonner, Brenda S.: 2000, "'A' is for Adjunct: Examining grade inflation in higher education", Journal of Education for Business, (September) v76, n1, p5.

23. Spinner, Jackie: 2003, "FASB Chief Says Congress is Meddling", The Washington Post, June 4, 2003, p E3.

24. Tyson, Thomas: 1990, "Believing that Everyone Else is Less Ethical: Implications for Work Behavior and Ethics Instruction" Journal of Business Ethics v9, n9, p. 715 -721.

25. Tyson, Thomas: 1992, "Does Believing that Everyone Else is Less Ethical have an Impact on Work Behavior?", Journal of Business Ethics v11, n9, p. 707 - 717.

26. Vam Valey, Thomas L. 2001: Recent Changes in Higher Education and their Ethical Implications, Teaching Sociology, v29, p 1.

27. Weber, James 1990: "Measuring the Impact of Teaching Ethics to Future Managers: A Review, Assessment, and Recommendations", Journal of Business Ethics v9, n3, p. 183 - 190.

28. Wynd, William R. and John Mager, 1989: "The Business and Society Course: Does it Change Student Attitudes?” Journal of Business Ethics v8, n6, p 487 - 491. 
NOTES 